\title{
Glasgow creates 'world's biggest smile'
}

The University of Glasgow's Dental School has created what it believes to be the world's biggest smile and is awaiting final verification that it has set a Guinness World Record.

Hundreds of people participated in the Big Smile Big Band event, which took place at the SEC Glasgow on 9 June 2017, including Dental School and other University staff, dental alumni, school children and teachers from the Glasgow area. Seven hundred and fifty-six participants wore red and white ponchos and formed the lips and teeth of a giant smile to highlight the importance of oral health.

During the event, lively interactive oral health promotion for school pupils in attendance was provided by the Glasgow Oral Health Improvement Student Society, and live music was provided by the Glasgow Dental School Big Band.

Professor Jeremy Bagg, Head of the Dental School at the University of Glasgow, said: 'I am delighted that we were able to achieve our aim of assembling such a large number of participants in the shape of a big smile as

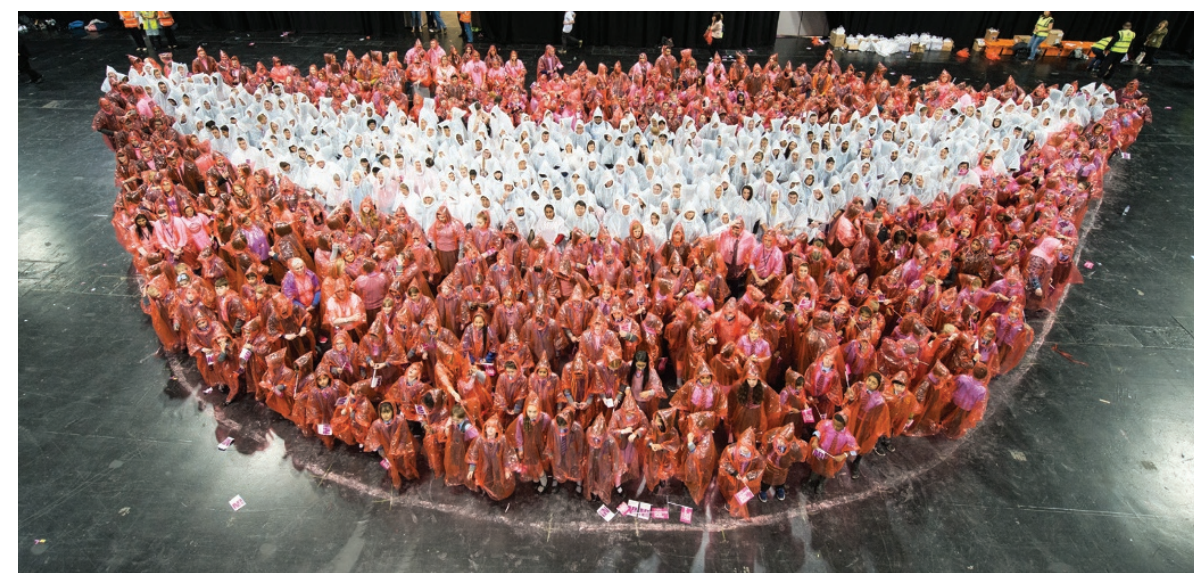

Glasgow's contribution to National Smile Month and I sincerely hope that Guinness World Records will verify this as the world's biggest smile. The event has been a huge amount of fun to organise and our sincere thanks go to all of the many partners and organisations involved who helped to make this happen. The promotion of oral health, particularly in children, is an important message to get across.'

The University of Glasgow event was organised in collaboration with CPD Scotland, Glasgow City Marketing Bureau, the SEC Glasgow, NHS Health Scotland/ Childsmile, NHS Greater Glasgow \& Clyde, Glasgow Dental Alumnus Association and Glasgow Oral Health Improvement Student Society. Thanks are due to the event's main financial sponsor, the British Endodontic Society, and supporters, Cordent, the Dental Defence Union and the Royal College of Physicians \& Surgeons of Glasgow.

\section{Cutting edge symposia to be held in Plymouth}

A provisional programme for the British Society for Oral and Dental Research's (BSODR's) 2017 Annual Meeting has been announced, with lectures from leaders in the field of dental research, cutting edge symposia and a variety of sessions and events.
The BSODR 2017 Annual Meeting is hosted by the University of Plymouth and will take place from 6-8 September.

The keynote lecture is to be delivered by Professor Jonathan Grant, Director of the Policy Institute at King's College London. His lecture, 'Assessing the impact of biomedical and health

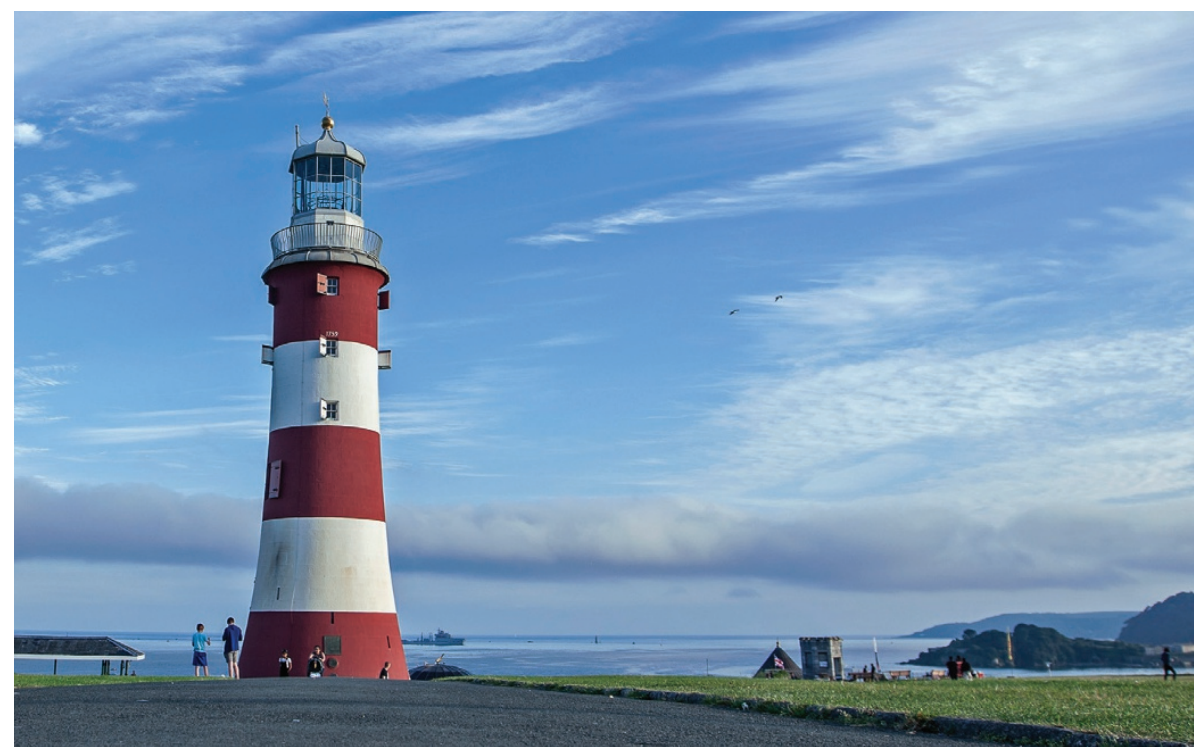

research, will look at why it is important to be able to assess the impact of biomedical and health research, and the different approaches for doing so. It will examine case studies from the UK Research Excellence Framework, including a sub analysis of those relating to dentistry, as well as reviewing other quantitative approaches. In conclusion, it will be argued that while research funding is effective in improving health, the same is not true for its efficiency in light of concerns about research waste.

The Annual Meeting will be a celebration of dental research, with oral sessions, poster sessions, and Colgate Prize and Unilever Poster Prize sessions.

The welcome reception will take place at the award-winning National Marine Aquarium and the conference dinner will be hosted at the historic Stonehouse Barracks, known as the 'spiritual home of the Royal Marines'.

Full details about the meeting are available at: www.plymouth.ac.uk/schools/ peninsula-school-of-dentistry/british-society-for-oral-and-dental-research-conference-2017. 